\title{
How to Improve Soil Anti-adhesion by Studying the Micro-topography of a Beetle Cuticle
}

\author{
M.O. Tesouro ${ }^{1}$, L. Venturelli ${ }^{1}$, M.A. Roba ${ }^{1}$, A. Romito ${ }^{1}$, L.M. Setten ${ }^{1}$ and E.A. Favret ${ }^{1,2}$ \\ 1. CNIA, INTA, Hurlingham, Argentina. \\ 2. CONICET, Buenos Aires, Argentina.
}

In the last thirty years, biomimetics (technological developments based on biological systems) has opened a fruitful field of investigation for engineering solutions. For instance, soil animals move without the soil sticking to them, basically because of their geometric shapes, hydrophobicity, lubrication and the micro-topography of the cuticular surface [1,2]. At the same time, farm workers know that the phenomenon of adherence of soil to solid surfaces, components of agricultural machinery, increases the required drawing force as well as energy consumption of machinery, decreasing the quality of work. Decreasing adhesion means replacing the soil-soil friction with friction between metal and soil, which can reduce the traction or drawing force on the tool with a consequent reduction in fuel consumption, but also the time window for carrying out plowing or tillage can be extended by reducing the required power. This has a deep ecological and economic impact resulting from saving fuel and labor time. Therefore, to overcome or reduce the adhesion of soil to solid surfaces, a solution based on the main characteristics of the micro-topography of the exoskeleton of the Diloboderus abderus beetle (female) is proposed (figure 1). Several images from the beetle's head and thorax (pronotum) were obtained using a scanning electron microscope FEI Quanta 200. Dimples with a seta in their center were seen on both sectors and they were the main feature of the beetle exoskeleton. Dimples were distributed in a random way over the head and thorax surfaces (figures 2 and 3). The mean diameter $2 r$ of the dimples was, for both head and thorax, $50 \pm 5 \mu \mathrm{m}$. The mean distance $d$ between dimples was $150 \pm 5 \mu \mathrm{m}$ for head and $250 \pm 5 \mu \mathrm{m}$ for thorax. Although the results obtained by other colleagues are not conclusive so far [3], we believed that dimples could be the primary cause of anti-adherence. As thorax is the main part of the beetle with a bigger area in contact to soil when the insect is digging and pushing, its data were used for designing a macro-topographic pattern for the upper surface of a steel shovel, the agricultural tool selected for the experiment. We chose the ratio $2 r / d=0.2(50 \mu \mathrm{m} / 250 \mu \mathrm{m})$ as the parameter to keep constant no matter the dimensions of the topographic pattern were. So, the pattern proposed for the shovel consisted on hemispherical dimples having a radius $r$ of $1 \mathrm{~mm}$, spaced apart a distance $d$ of 10 $\mathrm{mm}$ following a hexagonal (a common structure in nature) and homogeneous pattern over the entire tool surface (figure 4). The field tests were conducted on argiudoll soil from the Pampean region of Argentina in order to compare the traction force demand between a known ordinary smooth shovel and the biomimetic one, being both shovels of identical size and composition. Results indicated a reduction of the average traction demand of approximately $7 \%$ for the biomimetic tool. Presently more microscopic studies are being performed, as the analysis of other soil animal cuticles which could carry us to new anti-adhesion patterns [4].

\section{References:}

[1] LQ Ren et al, J. Agric. Eng. Research 79 (3) (2001), p. 239.

[2] J Tong et al, Soil \& Tillage Research 80 (2005), p. 1.

[3] T Satomi, H Nihei and H Takahashi, $15^{\text {th }}$ Int. Conf. on Experimental Mechanics (ICEM15), Conference Proceedings 2634 (2012), p. 1.

[4] Authors acknowledge the staffs of the Electronic Microscopy Laboratory (CAC - CNEA and INTA) for the micrographs. 


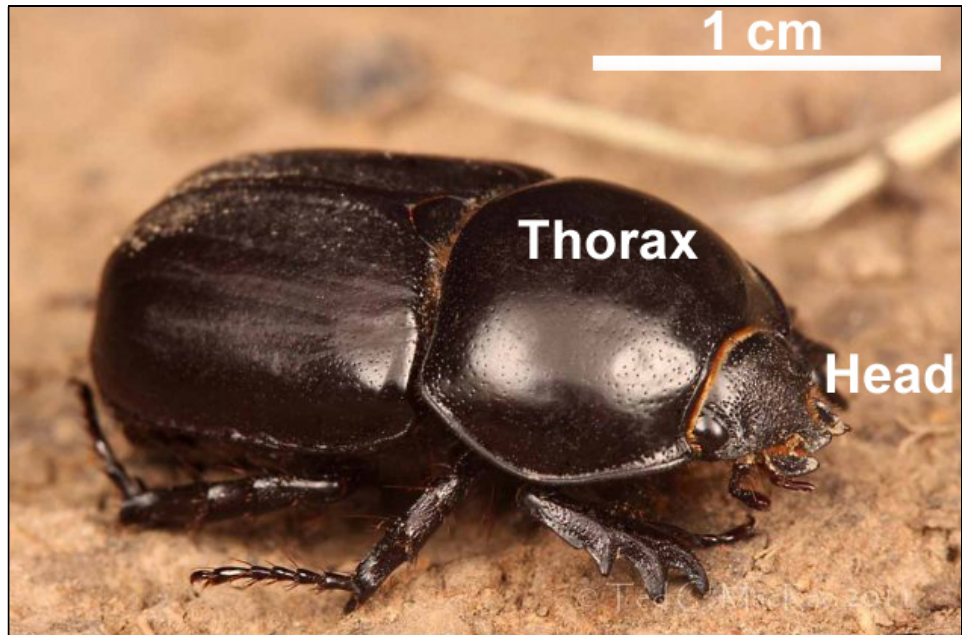

Figure 1. Diloboderus abderus beetle. Notice the dimples on the cuticle (Courtesy Ted MacRae).

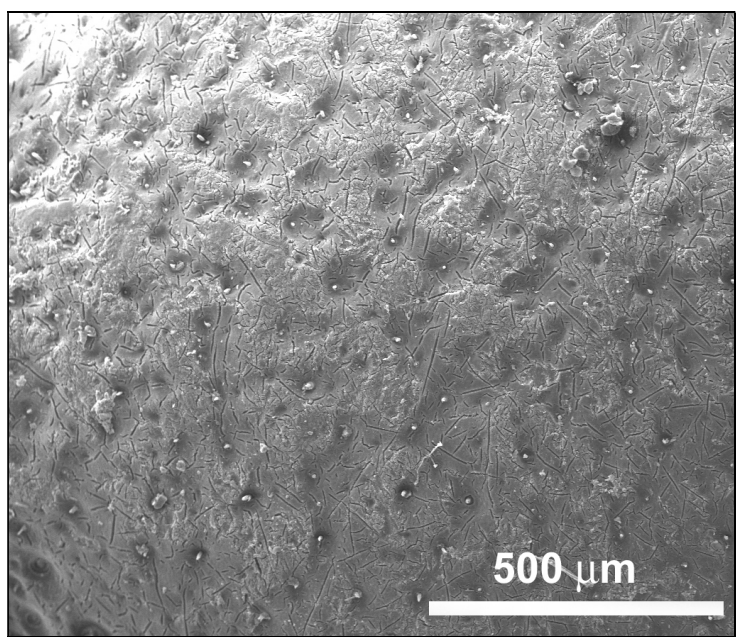

Figure 2. SEM micrograph of D. abderus head. Dimples are seen.

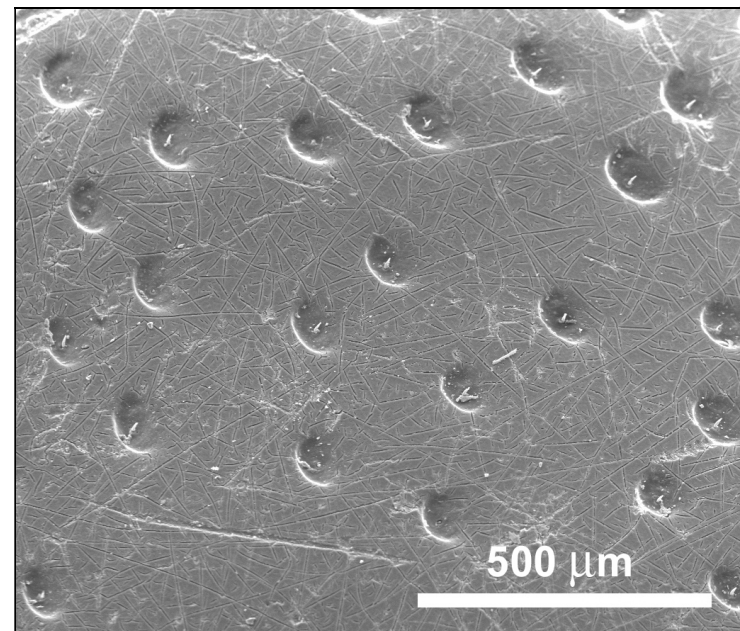

Figure 3. SEM micrograph of the thorax. Dimples are clearly seen.

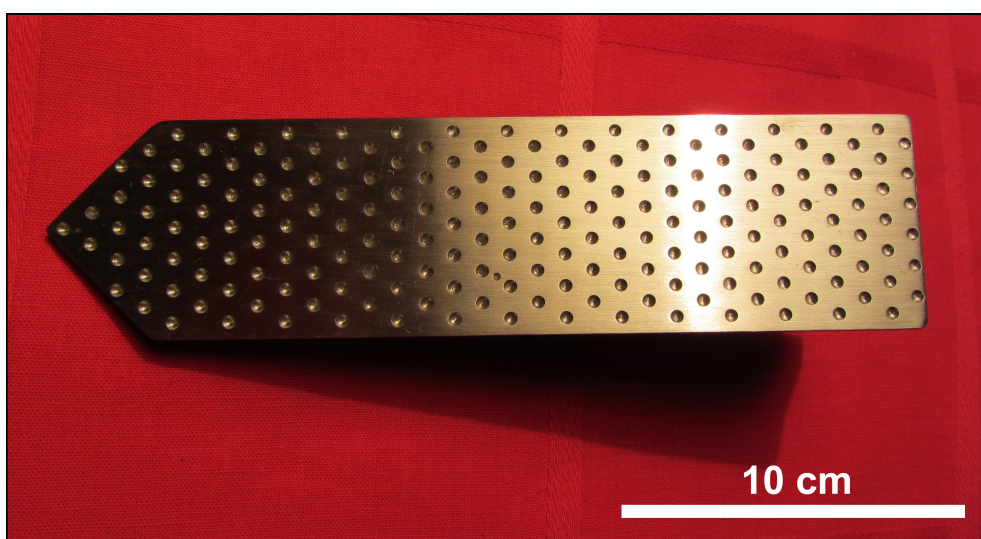

Figure 4. Biomimetic shovel with the pattern proposed. 